\title{
Mu-Opioid Stimulation in Rat Prefrontal Cortex Engages Hypothalamic Orexin/Hypocretin-Containing Neurons, and Reveals Dissociable Roles of Nucleus Accumbens and Hypothalamus in Cortically Driven Feeding
}

\author{
Jesus D. Mena, ${ }^{1,2 *}$ Ryan A. Selleck, ${ }^{1,2 *}$ and Brian A. Baldo ${ }^{1,2}$ \\ ${ }^{1}$ Neuroscience Training Program and ${ }^{2}$ Department of Psychiatry, University of Wisconsin-Madison, Madison, Wisconsin 53719
}

\begin{abstract}
Mu-opioid receptor ( $\mu \mathrm{OR}$ ) stimulation within ventral medial prefrontal cortex (vmPFC) induces feeding and hyperactivity, resulting possibly from recruitment of glutamate signaling in multiple vmPFC projection targets. We tested this hypothesis by analyzing Fos expression in vmPFC terminal fields after intra-vmPFC $\mu \mathrm{OR}$ stimulation, and by examining of the impact of glutamate receptor blockade in two feeding-related targets of vmPFC, the lateral-perifornical hypothalamic area (LH-PeF) and nucleus accumbens shell (Acb shell), upon behavioral effects elicited by intra-vmPFC $\mu$ OR stimulation in rats. Intra-vmPFC infusion of the $\mu$ OR agonist, DAMGO, provoked Fos expression in the dorsomedial sector of tuberal hypothalamus (including the perifornical area) and increased the percentage of Fos-expressing hypocretin/orexin-immunoreactive neurons in these zones. NMDA receptor blockade in the LH-PeF nearly eliminated intra-vmPFC DAMGO-induced food intake without altering DAMGO-induced hyperactivity. In contrast, blocking AMPA-type glutamate receptors within the Acb shell (the feeding-relevant subtype in this structure) antagonized intra-vmPFC DAMGO-induced hyperlocomotion but enhanced food intake. Intra-vmPFC DAMGO also elevated the breakpoint for sucrose-reinforced progressive-ratio responding; this effect was significantly enhanced by concomitant AMPA blockade in the Acb shell. Conversely, intra-Acb shell AMPA stimulation reduced breakpoint and increased nonspecific responding on the inactive lever. These data indicate intra-vmPFC $\mu$ OR signaling jointly modulates appetitive motivation and generalized motoric activation through functionally dissociable vmPFC projection targets. These findings may shed light on the circuitry underlying disorganized appetitive responses in psychopathology; e.g., binge eating and opiate or alcohol abuse, disorders in which $\mu$ ORs and aberrant cortical activation have been implicated.
\end{abstract}

\section{Introduction}

Central $\mu$-opioid receptors ( $\mu$ ORs) have been strongly implicated in natural- and drug-reward, addiction, and binge-type eating disorders (Kelley and Berridge, 2002; Bodnar, 2004; Haile et al., 2008; Gosnell and Levine, 2009; Berner et al., 2011). While reward-related opioid effects in subcortical structures have been extensively studied, much less is known about the cortical actions of opioids. Recent evidence suggests, however, that the prefrontal cortex (PFC) may be an important site of $\mu$-opioid peptide action. Positron emission tomography imaging studies have suggested a

\footnotetext{
Received July 12, 2012; revised 0ct. 14, 2013; accepted 0ct. 20, 2013.

Author contributions: B.A.B. designed research; J.D.M. and R.A.S. performed research; J.D.M. and B.A.B. analyzed data; J.D.M. and B.A.B. wrote the paper.

This project was supported by National Institute of Mental Health Grant MH074723 (B.A.B.) and National Research Service Award F31DA028104 (J.D.M.). R.A.S. was supported by training grant T32 GM007507 to the Neuroscience Training Program of University of Wisconsin-Madison. We thank Dr. Sarah Newman, Viridiana Estrada, Trina Basu, Abha Rajbhandari, Meaghan Bychowski, and Paria Karbassi for their technical assistance in these studies; Dr. Matthew Andrzejewski for assistance with computer programming for operant tasks; and Dr. Vaishali Bakshi for her helpful comments on this manuscript.

*J.D.M. and R.A.S. contributed equally to the present work.

Correspondence should be addressed to Dr. Brian A. Baldo, Department of Psychiatry, University of WisconsinMadison, 6001 Research Park Boulevard, Madison, WI 53719. E-mail: babaldo@wisc.edu.

DOI:10.1523/JNEUROSCI.3323-12.2013

Copyright $\odot 2013$ the authors $\quad 0270-6474 / 13 / 3318540-13 \$ 15.00 / 0$
}

functional role of PFC-localized $\mu \mathrm{ORs}$ in association with sweetened-alcohol consumption (Mitchell et al., 2012), acute psychostimulant administration (Colasanti et al., 2012), and cocaine craving (Gorelick et al., 2005). Nevertheless, at present, knowledge of the subcortical pathways through which intra-PFC $\mu \mathrm{OR}$ signaling influences motivated behavior (important for placing imaging results in a network context) is completely lacking.

We recently discovered that $\mu \mathrm{OR}$ stimulation, alone among a variety of other opioid and monoamine receptor manipulations within rat ventral medial PFC (vmPFC), elicits feeding behavior together with intense hyperactivity (an "eat-and-run" pattern; Mena et al., 2011). Unknown, however, are the vmPFC terminal fields that mediate these effects. The vmPFC is highly interconnected with structures that mediate diverse aspects of appetitively motivated behavior (Vertes, 2004; Gabbott et al., 2005). Prominent among these are the nucleus accumbens shell (Acb shell) and lateral-perifornical hypothalamic areas (LH-PeF), which represent among the densest of all vmPFC terminal fields (Vertes, 2004; Gabbott et al., 2005; Hahn and Swanson, 2010), and are the subcortical sites most frequently represented in bifurcating vmPFC projection neurons (Gabbott et al., 2005). The LH-PeF and Acb shell both strongly modulate appetitive behavior, but through dissociable mechanisms. Activation of the LH-PeF with 
glutamate agonists or electrical stimulation engenders feeding (Wise, 1974; Stanley et al., 1993; Berthoud and Münzberg, 2011; Li et al., 2011). In the Acb shell, however, blockade of AMPA-type glutamate receptors, or muscimol-induced inactivation, elicits overeating (via LH-PeF activation; Maldonado-Irizarry et al., 1995; Kelley and Swanson, 1997; Stratford and Kelley, 1999; Baldo et al., 2004), while electrical stimulation or AMPA receptor stimulation arrests feeding and promotes general motoric activation (Stratford et al., 1998; Ikeda et al., 2003; Krause et al., 2010). Hence, glutamate-mediated activation in LH-PeF versus Acb shell elicits dissociable behavioral processes; simultaneous recruitment of these conjointly innervated vmPFC projection targets could therefore contribute distinct (and potentially opposing) elements to the behavioral profile elicited by PFC $\mu$-opioid stimulation.

We tested this hypothesis with two complementary approaches. First, we mapped the subcortical distribution of Fos expression (including within the feeding- and arousal-related hypothalamic hypocretin/orexin (H/O) neurons) after infusion of $\mu$ OR agonist, DAMGO, into the vmPFC. Next, we performed dual-site microinfusion studies with simultaneous infusion of DAMGO into the vmPFC, and a glutamate receptor antagonist into the LH-PeF or AcbSh; we evaluated the ability of glutamate blockade in these PFC terminal fields to alter the DAMGOassociated behavioral profile. Our general goal was to begin to understand the subcortical pathways through which the behavioral effects of intra-PFC $\mu \mathrm{OR}$ transmissions are expressed.

\section{Materials and Methods}

All procedures were evaluated and approved by the Institutional Animal Care and Use Committee of the University of Wisconsin-Madison, and are in accordance with the guidelines promulgated in the NIH Guide for the Care and Use of Laboratory Animals. Facilities have been approved by the American Association for the Accreditation of Laboratory Animal Care.

Subjects. Male Sprague Dawley rats, obtained from Harlan, weighing 275-290 g upon arrival in the laboratory, were used in all experiments. Rats were pair-housed in clear polycarbonate cages $(9.5 \mathrm{in}$. width $\times 17$ in. length $\times 8$ in. height), with cob bedding, in a light- and temperaturecontrolled vivarium. Animals were maintained under a $12 \mathrm{~h} \mathrm{light/dark}$ cycle (lights on at 7:00 A.M.). Food (Agway rat-chow pellets) and water were available ad libitum. Animals were handled gently daily to reduce stress. Subjects were tested between the hours of 11:00 A.M. and 4:00 P.M., during the light phase of the animals' dark/light cycle.

Surgical procedures. Rats (weighing 300-330 g at the time of surgery) were anesthetized with isoflurane gas and secured in a Kopf stereotaxic frame. The toothbar was set at $-4.0 \mathrm{~mm}$ below the interaural line for all surgeries. Bilateral stainless steel cannulae (10 mm long, 23 gauge) were implanted according to standard stereotaxic procedures. For the vmPFC, coordinates of the injection site were the following: anteroposterior (AP): $+3.0 \mathrm{~mm}$ from bregma, mediolateral $(\mathrm{ML}): \pm 2.1 \mathrm{~mm}$ from midline, dorsoventral (DV): $-5.2 \mathrm{~mm}$ from skull surface with cannulae angled at 19 degrees from vertical to avoid damage to the medial wall of the PFC. Cannulae were fixed in place $2.5 \mathrm{~mm}$ above the target sites (for vmPFC) with dental acrylic (New Truliner) and anchoring skull screws (Plastics One). For the double cannulation studies, surgeries were performed on animals targeting vmPFC (as described above) and either LH-PeF or Acb shell. The vmPFC coordinates were the same as above. Angled placements were not used for the LH-PeF and Acb shell; for LH-PeF the coordinates were the following: AP: -3.14 from bregma, ML: $\pm 1.2 \mathrm{~mm}$ from midline, DV: -8.5 from the skull surface; for the Acb shell, AP: $+2.0 \mathrm{~mm}$ from bregma, ML: $\pm 1.0 \mathrm{~mm}$ from midline, DV: $-7.2 \mathrm{~mm}$ from skull surface. Wire stylets ( $10 \mathrm{~mm}$ long, 30 gauge) were placed in the cannulae to prevent blockage. Rats were given an intramuscular injection of penicillin $(0.3 \mathrm{ml}$ of a $300,000 \mathrm{U} / \mu \mathrm{l}$ suspension; Phoenix Pharmaceuticals), placed in heated recovery cages, returned to their home cages upon awakening, and given a recovery period of no less than $5 \mathrm{~d}$ (with daily health checks) before behavioral testing commenced.

Drugs. DAMGO, AP-5, and CNQX disodium salt hydrate were all obtained from Sigma-Aldrich and dissolved in sterile saline. For CNQX, the saline was warmed slightly during mixing to aid solubility.

Microinfusion procedures. For intracerebral microinfusions, rats were held gently, and stylets removed from the guide cannula. Stainless steel injectors, connected via polyethylene tubing (PE-10; Becton Dickinson) to $10 \mu \mathrm{l}$ capacity Hamilton syringes on a Harvard microdrive pump, were lowered to the site of infusion. The flow rate for infusions was 0.32 $\mu \mathrm{l} / \mathrm{min}$. The total infusate volume for the bilateral infusions was 0.5 $\mu \mathrm{l} / \mathrm{side}$. For the double cannulation studies, infusions into vmPFC preceded infusion into either LH or AcbSh by $\sim 5 \mathrm{~min}$. After infusions, injectors were left in place for an additional minute to allow for diffusion of the injectate into the tissue. Injectors were then removed and wire stylets replaced.

Feeding and locomotor activity measurements. Behavioral testing was performed in clear polycarbonate cages (9.5 in. width $\times 17$ in. length $\times$ 8 in. height) with wire-grid floors. Food intake and Fos experiments were conducted with ad libitum-maintained rats. Rats were tested two at a time, each rat in its own individual testing cage, and the testing sessions were videotaped. Videotaped behavioral testing sessions were scored by an experienced investigator blind to treatment, using an event recorder interfaced with a PC computer. The following behaviors were monitored: cage crossings, ambulation across the midpoint of the cage's long axis; rears, rearing up on the hind legs; grooming, cleansing of the face, paws, and body; feeding, uninterrupted bouts of chow-pellet intake; drinking, uninterrupted bouts of water intake. The frequency and duration of all these behaviors were recorded, except for cage crossings, for which only frequency was recorded. To record the duration of a given behavioral event, a switch was depressed on the event recorder that started an automatic timer (specific for that behavior) at the initiation of the behavior. The timer was switched off when the behavior was interrupted by a different behavior (for example, a rat engaged in a drinking bout stopping his drinking to rear or ambulate across the cage). From the frequency and duration data, the overall mean duration of each rearing, feeding, or drinking bout was calculated. Uneaten food and food spillage were recorded. The volume of water ingested was also recorded.

Progressive ratio task. Behavioral testing was performed in standard Plexiglas operant chambers housed in sound-attenuating cabinets. Ventilation fans in the chambers provided mild masking noise throughout the sessions. The chambers contained two retractable levers placed $6 \mathrm{~cm}$ apart, a pellet receptacle positioned between the levers, and three stimulus lights plus a house light positioned above the levers. Upon arrival in the laboratory, rats were food restricted and maintained at $90 \%$ of free-feeding body weight for initial operant training. Rats were then trained to lever press for $45 \mathrm{mg}$ sucrose pellets (BioServe). First, rats were exposed to a conjoint random time $30 \mathrm{~s} /$ fixed ratio 1 (RT-30/FR-1), with both levers extended. Only one lever was active; manipulating the inactive lever had no programmed consequences (but these presses were recorded). Depressing the active lever was followed by a pellet delivery into the food receptacle, a small light within the receptacle flashing briefly, and the house light turning off and the red stimulus light turning on for $5 \mathrm{~s}$. After this $5 \mathrm{~s}$ period the chamber returned to its "active" state (house light on, red light off).

Once rats were reliably retrieving sucrose pellets, the RT-30 component was removed. Rats were then trained progressively through FR-1, FR-3, and FR-5 schedules; once high rates of responding on FR-5 were achieved (at least 300 active lever presses/session), rats were switched to a progressive ratio-2 (PR-2) schedule. Here, the number of responses required for each successive reinforcer was increased by two (i.e., one response was required for the first pellet, three for the second, five for the third, etc.). After $2 \mathrm{~d}$ on the PR-2 schedule, rats were returned to ad libitum feeding, and henceforth received daily PR-2 sessions after acute, short-term food deprivation $(2 \mathrm{~h})$ immediately before the session. We found that this low level of food deprivation yielded highly stable responding, within a range that could be either increased or decreased by drug treatments. Rats were trained on PR-2 to stability ( $\pm 15 \%$ reinforcers earned on 3 consecutive days), whereupon they underwent cannula implantation surgery. Following at least $5 \mathrm{~d}$ of postoperative recovery, rats were returned to a schedule of daily PR-2 testing; when 
they again achieved stable baselines, drug infusions commenced as described in the following section.

\section{Experimental design}

Fos immunohistochemistry experiment Ad libitum-maintained rats with infusion cannulae aimed at the vmPFC were given at least $5 \mathrm{~d}$ to recover from surgeries. After this recovery period, they were habituated to the testing environment and testing conditions for 90 $\mathrm{min} / \mathrm{d}$ at least $5 \mathrm{~d}$ with no intracerebral manipulations. The testing environment consisted of clear polycarbonate cages with wire-grid floors, similar to the home cages but kept in a separate climate-controlled room with dim white lighting. Food and water were not provided in the testing cages at any stage of the experiment, because we aimed to investigate the subcortical activational effects of intravmPFC $\mu$-opioid stimulation per se, without the confounding effect of differing levels of ingestive behavior (and correspondingly different levels of oromotor activity, gustatory sensation, etc.) among the groups. Rats were given "sham injections" in which microinfusion injectors were lowered into the infusion cannula but not into the brain. The following day, saline infusions were administered into the brain site, and rats were placed in their home cages for $10 \mathrm{~min}$ and then in testing cages for $80 \mathrm{~min}$. These procedures served to habituate the rats to microinfusion and testing procedures. On test day, subsets of rats were infused bilaterally into the vmPFC with either saline $(n=7)$ or DAMGO $(2.5$ $\mu \mathrm{g} / 0.5 \mu \mathrm{l} ; n=7$ ) and were placed into their habitual testing cages. This dose was selected because it produced robust, consistent feeding responses in our prior work (Mena et al., 2011). Another subset of six rats received bilateral intra-vmPFC saline infusions and was placed into a novel environment, as a control for the general activating and arousing effects of intra-vmPFC $\mu$-opioid stimulation. The novel environment consisted of a room different from the room in which the animals were habituated previously and contained a white noise generator at $80 \mathrm{~dB}$ and two halogen lamps. The white noise generator and lamps were placed above and central to the testing cages. For all groups, rats remained in the test cages for $105 \mathrm{~min}$. Immediately following their testing sessions, rats were perfused under deep isoflurane anesthesia and their brains collected for immunohistochemical processing.

\section{Double-cannulation feeding/locomotion experiments}

After recovery from surgery, rats were handled for at least $5 \mathrm{~d}$ and received sham injections and intracerebral saline injections (see above). On the saline day, rats were placed into the testing cages (see above) with both preweighed quantities of chow pellets and water bottles for $30 \mathrm{~min}$. Two days later, drug testing commenced. We used a mixed betweensubjects/within-subjects design for drug testing, with intra-PFC saline or DAMGO as the between-groups factor, and a dose range of AP-5 (LH) or CNQX (Acb shell) as the within-subjects factor. For the vmPFC/LH-PeF double cannulation study, separate groups of ad libitum-maintained rats received either intra-vmPFC infusions of DAMGO $(2.5 \mu \mathrm{g} / 0.5 \mu \mathrm{l} ; n=6)$ or saline $(n=5)$. Both groups received counterbalanced intra-LH infusions of AP-5 $(0,0.25$, and $1.0 \mu \mathrm{g} / 0.5 \mu \mathrm{l})$ but the vmPFC-saline group received an additional dose of AP-5 $(0.5 \mu \mathrm{g} / 0.5 \mu \mathrm{l})$. We noted that intra$\mathrm{LH}-\mathrm{PeF}$ infusions of AP-5 in this dose range produced considerable sedation and motor suppression regardless of PFC treatment; hence, we conducted a second study with a much lower AP-5 dose. In this second study, two groups of ad libitum-maintained rats received either intravmPFC infusions of DAMGO $(2.5 \mu \mathrm{g} / 0.5 \mu \mathrm{l} ; n=11)$ or saline $(n=8)$ followed by intra-LH infusions of a very low AP-5 dose $(0.05 \mu \mathrm{g} / 0.5 \mu \mathrm{l})$ or saline.
Table 1. Fos counts in vmPFC projection target areas after intra-vmPFC saline, DAMGO $(2.5 \mu \mathrm{g} / 0.5 \mu \mathrm{l})$, or placement into a novel environment

\begin{tabular}{lll}
\hline Intra-vmPFC treatment & Acb core & Acb shell \\
\hline Saline & $243.4 \pm 81.1$ & $265.3 \pm 73.6$ \\
DAMG0 & $191.0 \pm 44.2$ & $260.6 \pm 26.5$ \\
Novel & $202.5 \pm 59.0$ & $424.7 \pm 110.3$ \\
& Anterior Acb & Thalamus \\
\hline Saline & $83.0 \pm 39.8$ & $516.4 \pm 160.8$ \\
DAMG0 & $20.33 \pm 9.7$ & $522.6 \pm 127.5$ \\
Novel & $83.0 \pm 20.7$ & $759.3 \pm 391.8$ \\
& BLA & CeA \\
\hline Saline & $265.4 \pm 70.8$ & $91.7 \pm 26.6$ \\
DAMG0 & $84.8 \pm 35.7$ & $94.6 \pm 42.2$ \\
Novel & $121.0 \pm 43.2$ & $68.7 \pm 25.7$ \\
& Hypothalamus (B) & Hypothalamus (C) \\
\hline Saline & $72.6 \pm 17.9$ & $74.3 \pm 18.1$ \\
DAMG0 & $60.1 \pm 15.3$ & $49.0 \pm 13.4$ \\
Novel & $31.3 \pm 8.7$ & $67.0 \pm 13.7$ \\
& Hypothalamus (D) & Arcuate nucleus (E) \\
\hline Saline & $143.3 \pm 26.4$ & $140.2 \pm 36.8$ \\
DAMG0 & $158.0 \pm 34.2$ & $239.8 \pm 34.3$ \\
Novel & $183.3 \pm 54.4$ & $159.7 \pm 38.2$ \\
\hline
\end{tabular}

Values denote means \pm SEM. Letters for hypothalamic regions denote ROIs defined in Figure 1.

The vmPFC/Acb shell experiment was performed according to the same general design. Separate groups of ad libitum-maintained rats were injected with either intra-vmPFC DAMGO $(2.5 \mu \mathrm{g} / 0.5 \mu \mathrm{l} ; n=6)$ or saline $(n=8)$. Both groups received counterbalanced intra-Acb shell infusions of $\operatorname{CNQX}(0,3,10,30$, and $100 \mathrm{ng} / 0.5 \mu \mathrm{l})$. For all experiments, unconditioned motor and ingestive behaviors were monitored and recorded for $30 \mathrm{~min}$ as described above in Feeding and locomotor activity measurements. Testing days were separated from each other by at least one interim day on which no drug infusions or behavioral testing oc- 

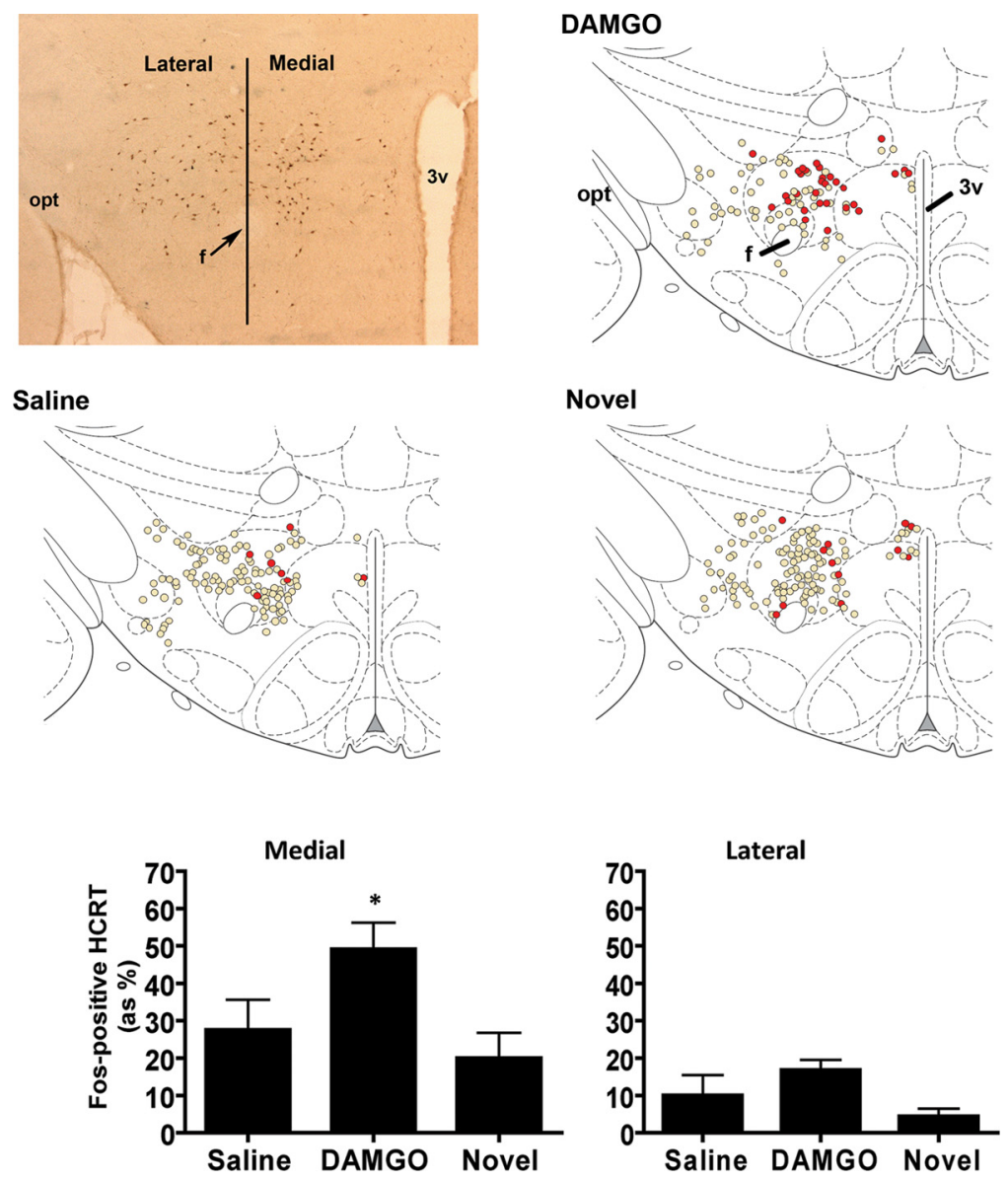

Figure 2. Photomicrograph at top left shows the tuberal hypothalamic area in which $\mathrm{H} / 0$ and Fos $+\mathrm{H} / 0$ double labeling was detected and counted. $\mathrm{H} / 0$ immunoreactive cells, stained with DAB, appear brown. To distinguish effects between the medial and lateral H/O neuron groupings, we bisected the fornix to form "medial" and "lateral" ROls, as shown here. Abbreviations are as defined in the Figure 1 legend. Line drawings of coronal brain sections (adapted from Paxinos and Watson, 2007) show positions of $\mathrm{H} / 0$-labeled cells (beige dots) and H/O-Fos double-labeled cells (red dots) plotted from representative brain sections for each group (see Materials and Methods for details). Graphs depict percentage Fos-positive H/O neurons in the medial and lateral ROls. Group sizes: saline, $n=7 ;$ DAMG0, $n=7$; novel environment, $n=6$. Error bars indicate 1 SEM; * $p<0.05$, relative to "saline" and "novel" groups in the medial zone.

curred. At the end of the experiment, rats were perfused transcardially with $10 \%$ formalin under deep isoflurane anesthesia.

Double-cannulation progressive ratio experiment

Rats $(n=5)$ received intra-vmPFC infusions of saline or DAMGO $(0.25 \mu \mathrm{g})$, and intra-Acb shell infusions of saline or CNQX (100 ng) according to a completely within-subjects design, with the order of drug treatments counterbalanced across subjects. After these treatments were completed, all rats received a challenge with saline in the vmPFC and AMPA (50 ng) in the AcbSh.

vmPFC infusions were always given first, followed 10 min later by intra-Acb shell infusions, whereupon rats were immediately placed into the operant chambers for the start of the session. Each drug-infusion day was separated from the next by at least two interim days, on which rats were tested on the PR-2 task with no intracerebral infusions.

\section{Immunochemistry}

After perfusion, brains were postfixed in a solution of $4 \%$ paraformaldehyde in $0.1 \mathrm{M}$ phosphate buffer overnight. Subsequently, brains were taken through graded sucrose solutions $(10 \%$ and $20 \%$ sucrose in $0.01 \mathrm{M}$ $\mathrm{PBS}, \mathrm{pH} 7.3$ ) at $4^{\circ} \mathrm{C}$ until they sank in the sucrose solutions $(96-120 \mathrm{~h})$. The brains were then frozen and $50 \mu \mathrm{m}$ coronal sections were taken through the entire neural axis on a cryostat microtome. Each section was retained in an individual well containing $0.1 \mathrm{M}$ PBS with $0.1 \%$ sodium azide and stored at $5^{\circ} \mathrm{C}$ for at least $24 \mathrm{~h}$. Alternating sections were stained to reveal Fos. Sections were washed in $0.01 \mathrm{M}$ PBS. Endogenous peroxidase activity was inhibited by incubating slides in a quenching solution containing $10 \%$ methanol and $0.75 \%$ hydrogen peroxide in $0.01 \mathrm{M}$ PBS for $10 \mathrm{~min}$ at room temperature. Sections were then washed again and incubated for $40 \mathrm{~h}$ at $4^{\circ} \mathrm{C}$ with primary rabbit anti-rat Fos antibody (Ab-5; EMD Millipore) diluted 1:5000 an antibody dilution buffer $(0.1 \%$ Triton X-100, $0.1 \%$ casein, and $0.1 \%$ sodium azide in $0.1 \mathrm{M}$ PBS, $\mathrm{pH}$ 7.2). After incubation, tissue was rinsed with $0.01 \mathrm{M}$ PBS, and then exposed to a goat antirabbit biotinylated secondary antibody (Vector Laboratories) for $2 \mathrm{~h}$. Tissue was rinsed with $0.01 \mathrm{M}$ PBS, exposed to an avidin-biotinperoxidase complex (ABC complex; Vector Laboratories) for $1 \mathrm{~h}$, rinsed again with $0.01 \mathrm{M}$ PBS, and stained with nickel-enhanced diaminobenzidine (DAB-Ni; Vector Laboratories) to yield a black precipitate. For dual immunohistochemical labeling of $\mathrm{H} / \mathrm{O}$ and Fos, hypothalamus-containing sections treated as just described were then washed in $0.01 \mathrm{M}$ PBS and exposed to a rabbit anti-rat prepro-orexin antibody (AB3096; EMD Millipore) diluted 1:2000 in the aforementioned antibody dilution buffer. Sections were exposed to the anti-prepro-orexin or antibody for $40 \mathrm{~h}$ at $5^{\circ} \mathrm{C}$. After incubation in the primary antibody, sections were rinsed with $0.01 \mathrm{M}$ PBS, and taken through all steps described above, except for the quench step. Tissue was exposed to diaminobenzidine (DAB) (Vector Laboratories), which stained $\mathrm{H} / \mathrm{O}$-containing neurons and processes a reddish-brown color. All sections were mounted on Fisher SuperFrost Plus slides (Fisher Scientific), air-dried for $24 \mathrm{~h}$, taken through graded alcohols (95-100\%), cleared in xylenes for $5 \mathrm{~d}$, and coverslipped with Permount (Fisher Scientific) mounting medium.

Light microscopy and image analysis For cell counting and evaluation of Fos localization, tissue sections were viewed with an Olympus U-SPT light microscope. Photomicrographs were taken with a microscope-mounted Hitachi HV-C20 CCD camera, interfaced with a PC-based computer. Using Scion-NIH Image, standardized shapes defining regions of interest (ROIs) for each anatomical region were superimposed on the images, and Fos-labeled cells were counted by an experienced investigator blind to treatment group. For the Acb shell, anterior Acb, basolateral amygdaloid nuclear group (BLA), central amygdaloid nuclear group (CeA), thalamus, and arcuate nucleus, polygons fitted to the contours of each individual nucleus were created, using prominent local fiber-bundle landmarks and consulting in-register cresyl violet-stained sections. For hypothalamic Fos counts outside the arcuate, the hypothalamus (at the tuberal level) was divided into quadrants using perpendicular lines centered on and bisecting the fornix; the resulting ROIs are shown in Figure 1. The thalamic ROI was a bowl-shaped region encompassing the central and lateral mediodorsal nuclei, the intermediodorsal nucleus, and paraventricular thalamic nucleus.

Cell counts for the double-labeling $\mathrm{H} / \mathrm{O} / \mathrm{Fos}$ study were conducted on a Leica DMI 6000B inverted microscope, using a Leica DC300F CCD camera interfaced to a PC-based computer to capture color images. Images were analyzed using ImagePro AMS v.6.1; a vertical line bisecting the fornix was used to divide the hypothalamic $\mathrm{H} / \mathrm{O}$ neuron population into medial and lateral sectors for counting. Cell counts were conducted by an investigator blind to treatment. Chartings of Fos-labeled H/O cells shown in Figure 2 were conducted by measuring the relative position of 
$\mathrm{H} / \mathrm{O}-$ labeled cells and cell clusters to prominent landmarks (fornix, mammillothalamic tract, optic tract, and third ventricle) in ScionNIH Image. Using Photoshop, cells were then plotted on a digital image of an in-register cresyl violet-stained section, and then on an atlas plate from an in-register atlas drawing. Images for publication were taken using Leica Application Suite software and imported in Adobe Photoshop version 5.0; contrast and sharpness were modified slightly to optimize the match between the digital images and the actual stained tissue.

\section{Verification of placements}

At the end of each cannulation experiment, rats were deeply anesthetized with isoflurane and perfused transcardially with a $0.9 \%$ saline solution followed by $10 \%$ formalin in phosphate buffer. Brains were collected and stored in 10\% formalin. Coronal sections $(60 \mu \mathrm{m})$ were cut through the infusion sites on a cryostat microtome, collected on slides, stained with cresyl violet, and subsequently reviewed to verify correct placement of the intracerebral injections. Images of representative sections from each experiment were captured using Scion Image software on a computer interfaced with a microscope-mounted Hitachi HV-C20 CCD camera.

\section{Statistical analyses}

Experiments were analyzed with two-factor or one-factor ANOVAs as appropriate. For the Fos immunoreactivity studies, one-factor (brain site) ANOVAs were used. Fisher's PLSD test or Bonferroni-corrected $t$ tests were used for post hoc comparisons among means. For all experiments, the level of statistical significance was set at $p<0.05$.

\section{Results}

Intra-vmPFC DAMGO infusion increases Fos expression in the dorsomedial sector of tuberal hypothalamus, including within $\mathrm{H} / \mathrm{O}$-immunoreactive neurons

To explore whether intra-vmPFC DAMGO infusion produces cellular activation in the hypothalamus and Acb shell, we examined Fos immunoreactivity in these sites, and surveyed several other subcortical terminal fields as well (anterior Acb, Acb core, mediodorsal thalamus, BLA and CeA) after intra-vmPFC $\mu$-opioid receptor stimulation. As shown in Figure 1, intravmPFC DAMGO significantly increased Fos expression within a dorsomedial portion of tuberal hypothalamus (including the medial part of the perifornical area), above the levels seen in salinetreated or novelty-exposed rats $\left(F_{(2,17)}=4.02 ; p<0.04\right)$. As summarized in Table 1 , however, there were no statistically significant effects of either intra-vmPFC DAMGO treatment or novelty exposure on Fos expression in any other of the terminal fields surveyed ( $F s=0.2-2.9$; n.s.). To follow up our observation that intra-vmPFC DAMGO increased Fos expression in an area known to contain a large subpopulation of $\mathrm{H} / \mathrm{O}$-containing neurons (Peyron et al., 1998; Baldo et al., 2004), we performed double-labeling immunohistochemistry for the detection of both Fos and H/O. As shown in Figures 2 and 3, intra-vmPFC DAMGO significantly increased the percentage of Fos-expressing $\mathrm{H} / \mathrm{O}$-containing neurons localized medially to the fornix $\left(F_{(2,17)}=\right.$ $4.2 ; p<0.04)$. There was no statistically significant increase in the percentage of Fos-positive $\mathrm{H} / \mathrm{O}$ neurons localized laterally to the fornix in DAMGO-treated rats $\left(F_{(2,17)}=2.6 ; p<0.1\right)$. Also, there were no differences in the total numbers of $\mathrm{H} / \mathrm{O}$ cells (Fos-positive or otherwise) counted among the groups, in either the medial or lateral ROIs ( $F_{\mathrm{S}}=0.1-0.5$, n.s.). These results suggest a top-down route of control (either the monosynaptic vmPFC-hypothalamus projection, or a polysynaptic pathway involving relays such as the amygdala or other structures) through which $\mu \mathrm{OR}$ signaling in the PFC could activate subgroupings of $\mathrm{H} / \mathrm{O}$ neurons, thereby
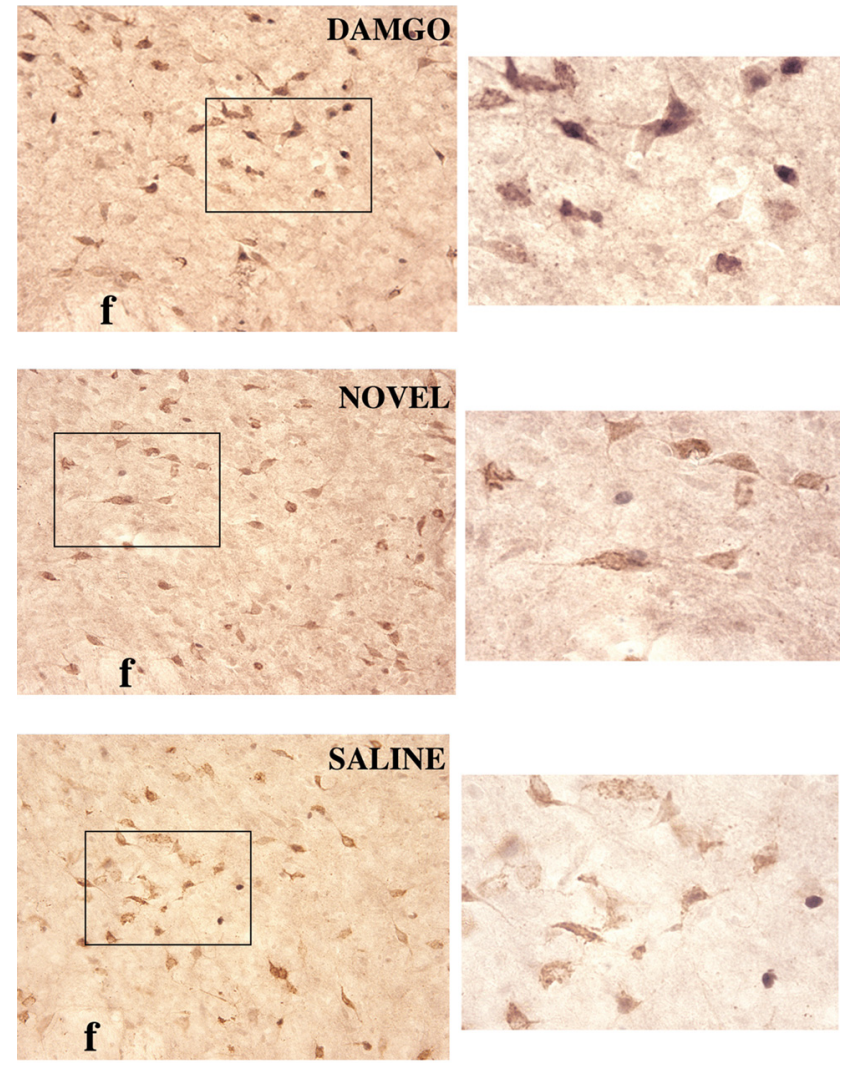

Figure 3. Photomicrographs depicting $\mathrm{H} / 0$ and Fos double staining in the dorsomedial tuberal hypothalamus, in the vicinity of the fornix ( $\mathrm{f}$ ), for intra-vmPFC DAMG0-treated rats, rats exposed to a novel environment, and intra-vmPFC saline-treated rats. Photomicrographs on the right side show high-magnification views of the boxed areas in the corresponding pictures on the left. H/O staining is brown, and black Fos staining appears in the cell nuclei. In these photomicrographs, medial lies to the right.

modulating arousal and appetitive behavior. Importantly, the $\mathrm{H} / \mathrm{O}$ population may not be the only peptide-coded neuron population to be activated; other systems (such as melaninconcentrating hormone) may be recruited as well and can be explored in future studies.

Interestingly, the dorsomedial tuberal hypothalamus was the only region among those surveyed in which intra-vmPFC $\mu$-opioid stimulation significantly enhanced Fos expression. This selectivity may reflect the prominence of the corticohypothalamic projection relative to other efferent pathways, although projections from vmPFC to ventral striatum and thalamus are also very dense (Gabbott et al., 2005). Caution is warranted in interpreting these negative results; for instance, it is possible that not every activated cell expressed Fos or that transcriptional activation and neuronal activation are not tightly coupled in the regions surveyed. Moreover, it has been shown that Fos does not track eliciting stimuli with perfect temporal fidelity (Khan and Watts, 2004). It will therefore be important to expand the current study in the future with other techniques for detecting downstream cellular activation (for example, the use of other markers of cellular activity). Finally, it is possible that the large degree of variability in some sites masked subtle effects that may have been apparent with larger sample sizes. Nevertheless, the present results clearly show that stimulation of vmPFC-localized $\mu \mathrm{ORs}$ augments the activity of a subgroup of $\mathrm{H} / \mathrm{O}$-containing neurons and that this was a substantial effect (Cohen's $d=1.4$ ). 

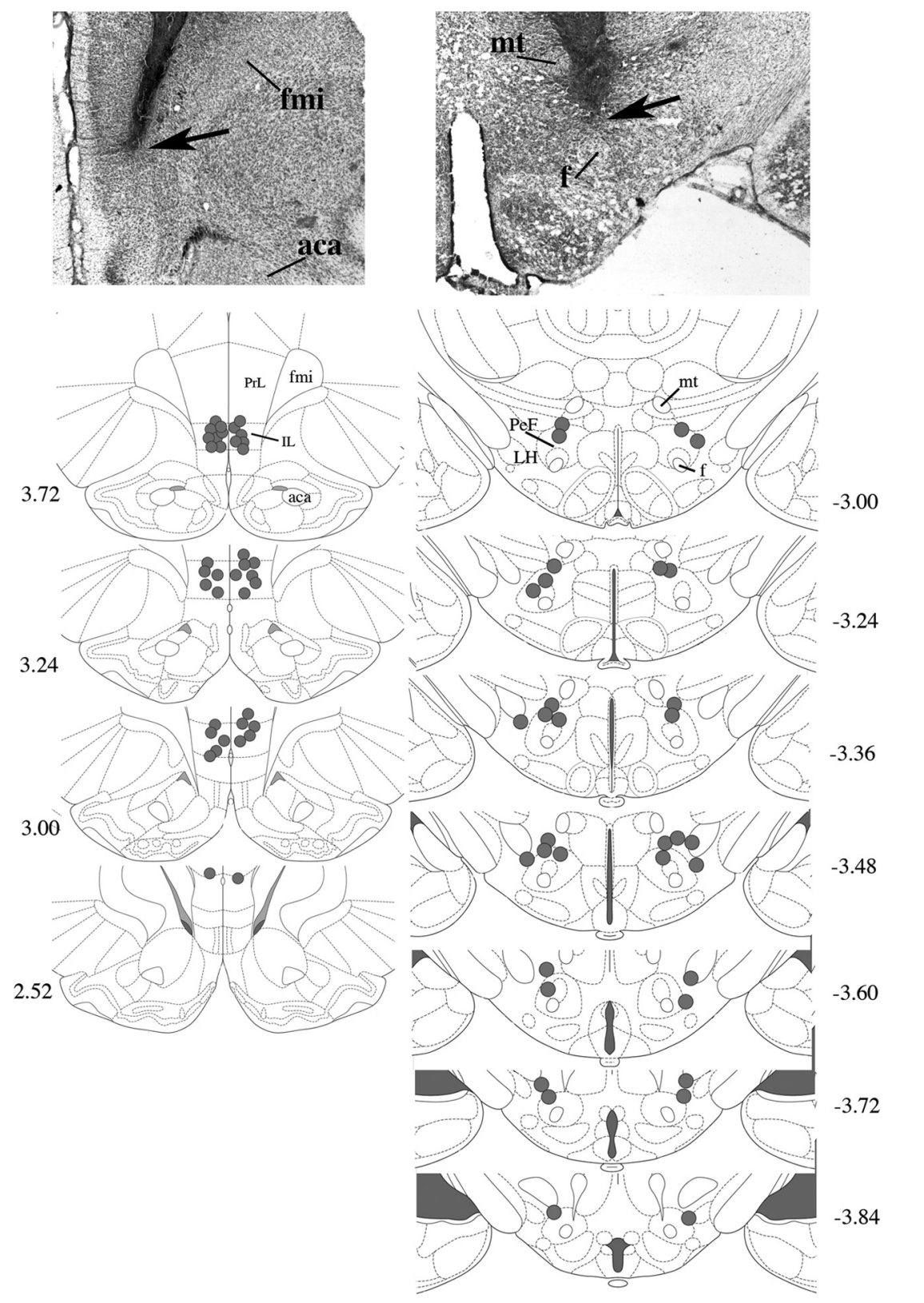

Figure 4. Injector placements for vmPFC/LH-PeF dual-cannulated animals. Photomicrographs at the top of each column show injector placements into vmPFC (left) and LH-PeF (right). Arrows indicate location of injector tips. Below the photomicrographs, line drawings of coronal sections (with position of each section given in millimeters from bregma) show injection sites from rats with bilateral placements in vmPFC and LH-PeF. Line drawings are adapted from Paxinos and Watson (2007). Gray dots represent the locations of injector tips. PrL, prelimbic area; IL, infralimbic area; fmi, corpus callosum, anterior forceps; aca, anterior commissure; mt, mammillothalamic tract; $\mathrm{f}$, fornix, PeF, perifornical area; LH, lateral hypothalamic area.

Intra-LH-PeF low-dose NMDA receptor blockade reverses intra-vmPFC DAMGO-induced increases in food intake, but this dose does not alter DAMGO-induced hyperlocomotion To explore the effect of glutamate receptor blockade in the LH-PeF on the intra-vmPFC DAMGO-induced behavioral phenotype, we combined intrahypothalamic infusions of the competitive NMDA receptor antagonist, $\mathrm{AP}-5(0,0.25,0.5$, and 1.0 $\mu \mathrm{g} / 0.5 \mu \mathrm{l})$ with intra-vmPFC infusion of DAMGO $(2.5 \mu \mathrm{g} / 0.5$ $\mu \mathrm{l})$ or saline. The area targeted was the perifornical region and medial part of the LH (Fig. 4 for placements), where strong feeding responses were obtained in prior studies (Stanley et al., 1993). Our objective was to establish evidence of a functional

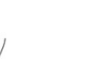

$-3.48$

$-3.60$

$-3.60$

glutamate-coded vmPFC-hypothalamus interaction; hence, we conducted our inquiry with the NMDA subtype because of the extensive work implicating hypothalamic NMDA receptors in feeding behavior (Stanley et al., 1993, 1996; Duva et al., 2002). Other glutamate receptors may be involved but we felt the NMDA subtype was a good place to start to establish proof of principle for an opioid-coded PFC-hypothalamus interaction in appetitive behavior. Because visual observation revealed that intra-LH-PeF infusions of AP-5 in this dose range made the animals lethargic and sedated, as confirmed in the statistical analyses showing significant main effects of AP-5 $\left(F_{(2,27)}=32.4, p<\right.$ 0.0001 for feeding; $F_{(2,17)}=3.3, p<0.05$ for locomotion; data not shown), we were concerned that the reduction in feeding behavior may have resulted from a generalized motoric impairment.

Thus, in another set of animals, we tested DAMGO in the vmPFC against a low dose of AP-5 $(0.05 \mu \mathrm{g} / 0.5 \mu \mathrm{l})$-20-fold lower than commonly used in the literature (Dalley et al., 2005; McKee et al., 2010)—in the LH-PeF (placements for this experiment are shown in Fig. 4). As expected, food intake was significantly increased by intra-vmPFC DAMGO, and this feeding effect was almost completely eliminated by the low dose of intra-LH-PeF AP-5 (Fig. 5). Statistical analyses revealed a main effect of vmPFC DAMGO $\left(F_{(1,17)}=8.2 ; p<0.02\right)$ and a main effect of LH AP-5 $\left(F_{(1,17)}=9.0 ; p<\right.$ 0.009 ), but surprisingly no interaction $\left(F_{(1,17)}=3.3, p<0.09\right)$. Nevertheless, given the presence of multiple, clear main effects and an experimental design strongly driven by our a priori hypothesis, we conducted post hoc comparisons among individual means that were not collapsed across either factor. Bonferroni-corrected $t$ tests $(\alpha-$ level $=0.0125)$ revealed that intra-LH-PeF infusion of AP-5 strongly attenuated the intra-vmPFC DAMGO-induced feeding effect, but AP-5 did not alter feeding in intravmPFC saline-treated rats (for a summary of specific comparisons, see Fig. 5). A similar pattern of results was noted for total eating duration, as summarized in Table 2. Together, these data show that AP-5 antagonized the DAMGO-induced increase in food intake, demonstrating a glutamate-coded functional interaction between the two brain sites in the control of feeding behavior. In contrast, for locomotor activity (Fig. 5), analyses showed a main effect of DAMGO $\left(F_{(1,17)}=5.6, p<0.04\right)$ but no effect of AP-5 $\left(F_{(1,17)}=0.7\right.$, n.s. $)$ and no AP-5 $\times$ DAMGO interaction $\left(F_{(1,17)}=0.05\right.$, n.s. $)$. Indeed, no other effects on any other DAMGO-associated behaviors, such as grooming, drinking, or rearing, were detected following administration of this very low dose of AP-5 into the LH-PeF (data not shown). Together, these results show that pharmacological blockade of NMDA- 
subtype glutamate receptors in the LH$\mathrm{PeF}$, via administration of low-dose AP-5, selectively reduces food intake while leaving DAMGO-induced hyperactivity unaffected. This finding suggests that the intra-vmPFC DAMGO-induced increase in food intake is dependent upon transmission through NMDA-type glutamate receptors in the $\mathrm{LH}-\mathrm{PeF}$, but the hyperactivity is mediated by other neurotransmitter receptors and/or brain sites.

\section{Intra-Acb shell infusion of CNQX functionally antagonizes intra-vmPFC DAMGO-induced hyperactivity but augments (additively) DAMGO- induced food intake}

To investigate the role of glutamate signaling in the Acb shell in subserving the behavioral effects of intra-vmPFC DAMGO, we injected a dose range of the AMPA-subtype glutamate receptor antagonist CNQX (0, 3.0, 10.0, 30.0, and 100.0 $\mathrm{ng} / 0.5 \mu \mathrm{l}$ ) into the Acb shell of ad libitum-maintained animals and coinfused the same animals with either DAMGO $(2.5 \mu \mathrm{g} /$ $0.5 \mu \mathrm{l}$ ) or saline in the vmPFC (for placements, see Fig. 6). CNQX was selected instead of AP-5 because it has been shown that, in the Acb shell, the AMPA receptor subtype (as opposed to NMDA) is involved in mediating feeding behavior (Maldonado-Irizarry et al., 1995). A complexity in the present study is the fact that both intra-vmPFC DAMGO and intraAcb shell CNQX induce feeding on their own. Hence, we tested a wide dose range of CNQX, consisting of doses subthreshold and near-threshold for feeding, to better evaluate the interaction between the two drugs in the two sites.

For food intake, the interaction between intra-vmPFC DAMGO and intra-Acb shell CNQX was simply additive. As can be seen in Figure 7, both drugs augmented feeding with no interaction between them (main effect of DAMGO: $F_{(1,12)}=6.5, p<$ 0.03; main effect of CNQX: $F_{(4,48)}=6.3, p<0.001$; DAMGO $\times$ CNQX interaction: $F_{(4,48)}=0.05$, n.s.). Similar effects (i.e., two main effects with no interaction) were seen for measures of feeding microstructure, as summarized in Table 3.

However, for locomotor activity (Fig. 7), there was a highly significant interaction between the two treatments $\left(F_{(4,48)}=5.9\right.$, $p<0.001)$ in addition to the expected main effect of DAMGO $\left(F_{(4,48)}=40.6, p<0.001\right)$, but no main effect of CNQX $\left(F_{(4,48)}=\right.$ 0.7 , n.s.). Fisher's PLSD test showed that activity levels provoked by $100 \mathrm{ng} C \mathrm{NQX}$ were significantly higher than that for all other doses ( $p$ s $<0.0001)$, and the $30 \mathrm{ng}$ dose was higher than the $3 \mathrm{ng}$ dose $(p=0.046)$. For the DAMGO group, Fisher's test detected a marginally significant decrease between DAMGO/saline and DAMGO/CNQX $100(p=0.0503)$. Next, we conducted Bonferroni-corrected $t$ tests $(\alpha$-level $=0.007)$ to compare the difference between rats treated with intra-vmPFC DAMGO versus saline, and also to compare DAMGO/saline to DAMGO/ CNQX $100 \mathrm{ng}$, and saline/saline to saline/CNQX $100 \mathrm{ng}$. These tests revealed significant differences between intra-vmPFC saline and intra-vmPFC DAMGO at all doses of CNQX, except for the highest dose. At this CNQX dose, the mean locomotor activity values for intra-vmPFC saline and intra-vmPFC DAMGO were nearly identical. Moreover, there was a significant reduction in activity in DAMGO/CNQX 100 ng compared with DAMGO/saline, and an
Table 2. Feeding microstructure effects following infusion of either DAMGO (2.5 $\mu \mathrm{g} / 0.5 \mu \mathrm{l}$ ) or saline into vmPFC and a low dose of AP-5 into the LH-PeF of $a d$ libitum-maintained rats

\begin{tabular}{lcc}
\hline AP-5 LH-PeF $(\mu \mathrm{g} / 0.5 \mu \mathrm{l})$ & Saline vmPFC & DAMGO vmPFC $^{*}$ \\
\hline Eating bouts & & \\
$\quad 0.0$ & $9.1 \pm 3.3$ & $42.2 \pm 8.3$ \\
$\quad 0.05$ & $6.0 \pm 2.3$ & $31.5 \pm 7.8$ \\
Total eating duration(s) & & \\
$\quad 0.0$ & $71.9 \pm 31.2$ & $264.8 \pm 60.4$ \\
$\quad 0.05^{\#}$ & & $107.3 \pm 27.1$ \\
Mean eating bout duration(s) & $7.9 \pm 2.0$ & \\
0.0 & $12.7 \pm 7.6$ & $8.7 \pm 2.3$ \\
0.05 & & $2.9 \pm 0.6$ \\
\hline
\end{tabular}

Values represent mean \pm SEM. ${ }^{*} p<0.05$, main effect of vmPFC/DAMGO; ${ }^{*} p<0.05$, main effect of LH-PeF/Ap-5.

increase in activity in saline/CNQX 100 ng compared with saline/saline.

Together, these analyses indicate that both DAMGO and CNQX increase activity, but that the combination of DAMGO plus the highest CNQX dose is not different from that dose of CNQX alone, and, indeed, is lower than DAMGO alone. This represents infra-additivity between DAMGO-induced hyperactivity and CNQX: induced hyperactivity (i.e., both effects were in the same direction-increased activity, but their sum was no greater than either effect alone). This is interpreted as a functionally antagonistic interaction between the two treatments (Wessinger, 1986; Woolverton, 1987). Importantly, no focal stereotypes or any unusual motor syndromes were noted with the DAMGO/100 ng CNQX combination.

It could be proposed that the activity decrease in the intravmPFC DAMGO-treated rats at the highest CNQX dose could have arisen simply from behavioral competition between locomotion and feeding. This would be true if, at the DAMGO/100 ng CNQX combination, the rats were spending so much time eating that they were no longer able to locomote at DAMGO-alone levels. However, this is unlikely. First, mean food intake at the DAMGO/100 ng CNQX dose combination was between 3 and $4 \mathrm{~g}$ in $30 \mathrm{~min}$. We routinely see much higher rates of feeding with muscimol in the Acb shell (on the order of twice as much; Stratford and Kelley, 1999; Baldo et al., 2005), indicating that rats in the present experiment were nowhere near their ceiling for feeding. It is therefore unlikely that, at the DAMGO/100 ng CNQX combination, feeding dominated the behavioral repertoire to 

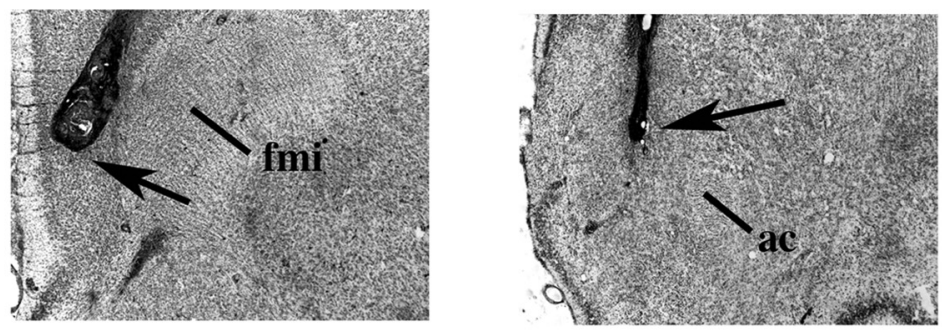

3.72
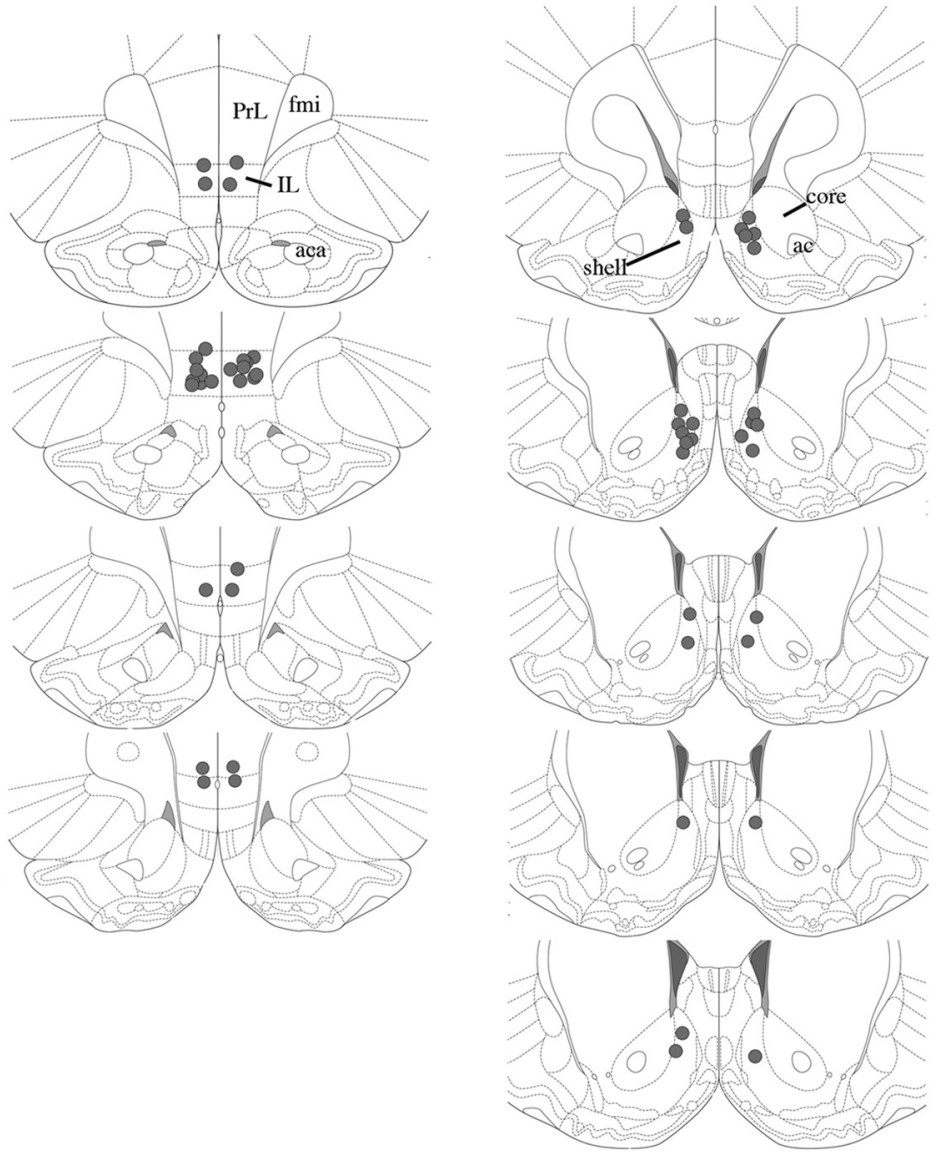

3.00

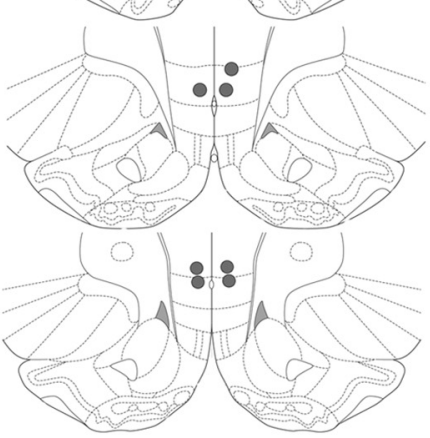

2.76

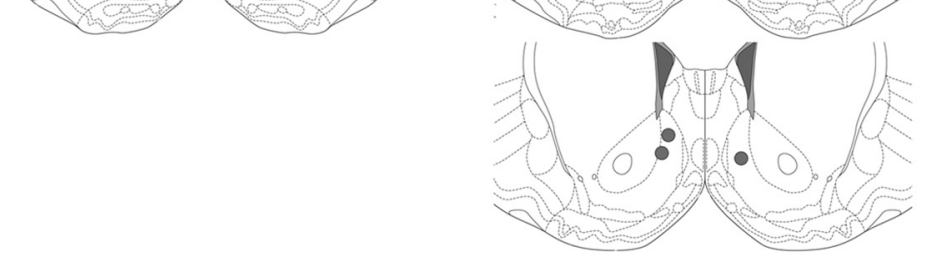

Figure 6. Injector placements for $\mathrm{PmPF} / \mathrm{Acb}$ shell dual-cannulated animals. Photomicrographs at the top of each column show injector placements into vmPFC (left) and Acb shell (right). Arrows indicate location of injector tips. Below the photomicrographs, line drawings of coronal sections (with position of each section given in $\mathrm{mm}$ from bregma) show injection sites from rats with bilateral placements in vmPFC and Acb shell. Gray dots represent the locations of injector tips. Line drawings are adapted from Paxinos and Watson (2007). Abbreviations are as defined in the Figure 4 legend.

such a degree as to render the rats unable to locomote at the level seen with DAMGO alone. Second, a regression analysis on $\Delta$ food intake versus $\Delta$ locomotor counts between the DAMGO/ saline and DAMGO/100 ng CNQX dose combinations showed no relationship between the magnitude of changes in feeding versus locomotion $\left(R^{2}=0.06\right)$; an $F$ test showed that the slope of the regression function was not significantly different from zero $\left(F_{(1,4)}=0.23 ;\right.$ n.s. $)$. However, a $t$ test showed that mean activity levels for these two data points were significantly different (mentioned above). If increased feeding caused the dip in locomotor activity (by simple behavioral competition), one would have expected to find a relationship between the two variables in the regression analysis.

Collectively, these results demonstrate that blockade of AMPA-subtype glutamate receptors in the AcbSh selectively reduces intra-vmPFC DAMGO-induced increases in locomotor activity while augmenting (additively) DAMGO-induced increases in food intake. Another complexity, however, is that
2.52

1.80

CNQX-induced AMPA receptor blockade also increased locomotor activity (slightly) at the highest dose. It should be noted that general activity associated with CNQX or muscimol inactivation of the Acb shell is, to a significant degree, food directed (e.g., food approach and food carrying; B.A. Baldo and A.E. Kelley, unpublished observations). In contrast, direct intra-Acb shell AMPA stimulation suppresses feeding behavior while simultaneously engendering locomotor hyperactivity and rearing behavior (Stratford et al., 1998). Based on these considerations, the present findings support the interpretation that intra-Acb shell AMPA receptor blockade antagonized a glutamate signal arising from intra-vmPFC $\mu$-opioid stimulation; the effect of this glutamate signal in the Acb shell is to induce a repertoire of general motor activation and to "restrain" feeding; at extreme levels this AMPA signal eliminates feeding (Stratford et al., 1998). This interpretation is not inconsistent with recent findings that electrical stimulation of the Acb shell "arrests" feeding (Krause et al., 2010).

\section{Intra-vmPFC DAMGO augments sucrose-reinforced $P R$ responding; intra-AcbSh infusion of CNQX potentiates this effect while intra-Acb shell AMPA reduces breakpoint and engenders nonspecific lever pressing} To further examine the complex betweensite interactions described above, we performed a parallel vmPFC/Acb shell double-cannulation experiment using the PR task (example placements are shown in Fig. 8) We explored the interaction of $0.25 \mu \mathrm{g}$ DAMGO (which we found to optimally modify PR responding in preliminary experiments; data not shown) with the most effective CNQX dose from the feeding/locomotion study described above (100 ng). As shown in Figure 8, Intra-vmPFC DAMGO robustly elevated PR responding on the active lever; this finding is not inconsistent with the recent observation that intra-PFC naltrexone reduces food-reinforced $P R$ responding (Blasio et al., 2013). The DAMGO-induced potentiation of PR was markedly potentiated by the $100 \mathrm{ng}$ intraAcb shell CNQX dose (main effect of DAMGO: $F_{(1,4)}=41.1$; $p<0.004$; CNQX: $F_{(1,4)}=6.4 ; p<0.07$; DAMGO $\times$ CNQX: $\left.F_{(1,4)}=11.0 ; p<0.03\right)$. Indeed, total lever presses for the DAMGO + CNQX combination often exceeded 1000 presses per session. Responding on the inactive lever was low for all groups (in the range of 1-7 presses), but elevated slightly by CNQX and the DAMGO + CNQX combination (main effect for DAMGO: $F_{(1,4)}=3.2$, n.s.; CNQX: $F_{(1,4)}=12.2 ; p<0.03$; DAMGO $\times$ CNQX: $\left.F_{(1,4)}=5.8 ; p<0.08\right)$.

Next, all rats were challenged with AMPA in the Acb shell (and saline in the vmPFC); AMPA effects were compared with all other treatments using one-way ANOVAs followed by Fisher's PLSD 

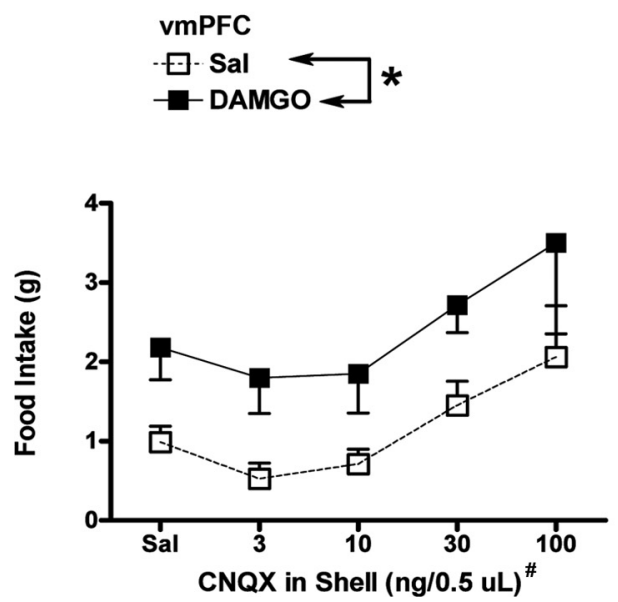

vmPFC

- Sal

- DAMGO

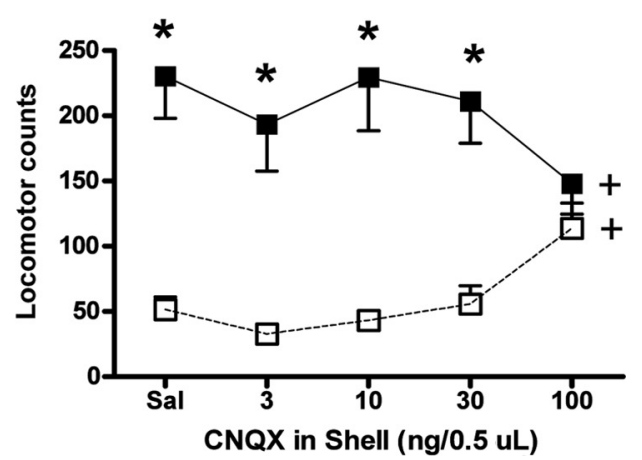

Figure 7. Effects of AMPA receptor blockade in the AcbSh (with CNQX) on intra-vmPFC DAMG0-induced changes in behavior. Left: Food intake effects following infusion of either DAMGO (2.5 $\mu \mathrm{g} / 0.5 \mu \mathrm{l}$ ) or saline (Sal) into vmPFC and CNQX into the AcbSh of ad libitum-maintained rats. Right: Locomotor activity effects in the same rats. Group sizes: saline, $n=8 ;$ DAMG0, $n=6$. Left: ${ }^{*} p<$ 0.05 , main effect of DAMGO; $\# p<0.05$, main effect of CNQX. Right: ${ }^{*} p<0.05$, different from corresponding intra-vmPFC saline value. Plus signs indicate significant differences $(p<0.05)$ between $100 \mathrm{ng}$ CNQX and saline, for both the vmPFC Saline and DAMG0 groups. Error bars indicate 1 SEM.

Table 3. Feeding microstructure effects following infusion of either DAMGO ( 2.5 $\mu \mathrm{g} / 0.5 \mu \mathrm{l})$ or saline into vmPFC and doses of CNQX into the AcbSh of ad-libitum maintained rats

\begin{tabular}{lcc}
\hline CNQX Acb shell $(\mathrm{ng} / 0.5 \mu \mathrm{l})$ & Saline vmPFC & DAMGO vmPFC $^{*}$ \\
\hline Eating bouts $^{\#}$ & & \\
0.0 & $9.3 \pm 2.1$ & $27.2 \pm 3.0$ \\
3.0 & $5.9 \pm 1.7$ & $21.3 \pm 4.2$ \\
10.0 & $10.8 \pm 4.2$ & $19.8 \pm 4.7$ \\
30.0 & $11.4 \pm 2.4$ & $31.8 \pm 2.4$ \\
100.0 & $20.5 \pm 6.8$ & $39.0 \pm 14.0$ \\
Total eating duration (s) & & \\
0.0 & $155.1 \pm 35.2$ & $207.9 \pm 56.0$ \\
3.0 & $88.2 \pm 48.2$ & $202.8 \pm 57.8$ \\
10.0 & $100.0 \pm 33.9$ & $221.5 \pm 62.6$ \\
30.0 & $231.7 \pm 48.5$ & $340.6 \pm 49.8$ \\
100.0 & $227.6 \pm 74.2$ & $440.0 \pm 147.0$ \\
Mean eating bout duration (s) & & \\
0.0 & $18.4 \pm 5.3$ & $7.8 \pm 1.8$ \\
3.0 & $10.2 \pm 5.2$ & $9.8 \pm 2.3$ \\
10.0 & $10.2 \pm 2.4$ & $12.9 \pm 4.0$ \\
30.0 & $23.1 \pm 5.9$ & $10.7 \pm 1.5$ \\
100.0 & $9.1 \pm 2.4$ & $11.5 \pm 2.9$ \\
\hline
\end{tabular}

Values represent mean \pm SEM. ${ }^{*} p<0.05$, main effect of $v m P F C / D A M G 0$ for Eating bouts and Total eating duration; ${ }^{\#} p<0.05$, main effect of AcbSh/CNQX.

post hoc tests. Intra-Acb shell AMPA significantly reduced PR responding on the active lever $\left(F_{(4,16)}=24.8 ; p<0.0001\right)$ and substantially increased responding on the inactive lever $\left(F_{(4,16)}=\right.$ $4.5 ; p<0.02$ ). Post hoc comparisons (Fig. 8) indicated that these AMPA effects differed significantly from the effects of saline into both sites, CNQX into the Acb shell, or DAMGO into the vmPFC. To further explore the possibility that intra-Acb shell AMPA degraded stimulus control in the PR task, we calculated a leverdiscrimination index (active lever presses/total lever presses) in which indiscriminate responding is indicated by a value of 0.5 . AMPA significantly reduced lever discrimination relative to all other groups $\left(F_{(4,16)}=3.5 ; p<0.04\right)$. Together, these findings with the PR task further indicate that AMPA signaling in the Acb shell "opposes" specific goal-directed appetitive behaviors associated with intra-vmPFC $\mu$-opioid signaling by provoking a competing behavioral set of generalized, indiscriminate motor activation.
Histological verification of intra-tissue injection placements Representative micrographs of injector placements into vmPFC and LH-PeF (Fig. 4), and into vmPFC and AcbSh (Figs. 6, 8) of dual-cannulated animals reveal that cannula and injector tracks are clearly visible with no unusual damage to the targeted areas.

\section{Discussion}

Summary of results

Several novel results were obtained in the current study. First, intra-vmPFC DAMGO infusion provoked Fos expression within dorsomedial tuberal hypothalamus, and increased the activation of $\mathrm{H} / \mathrm{O}$-containing neurons in this zone. Second, feeding behavior elicited by intra-vmPFC $\mu \mathrm{OR}$ stimulation was nearly eliminated by blockade of NMDA-type glutamate receptors in the $\mathrm{LH}-\mathrm{PeF}$ with a low dose of AP-5. This dose did not, however, alter the hyperactivity induced by intra-vmPFC DAMGO administration. Finally, blockade of AMPA-type glutamate receptors in the Acb shell with CNQX facilitated intra-vmPFC DAMGO-induced feeding and markedly potentiated DAMGO-induced enhancement of sucrose-reinforced $\mathrm{PR}$ responding. Moreover, intra-Acb shell CNQX functionally antagonized the hyperactivity engendered by intra-vmPFC DAMGO. Finally, in the PR task, stimulation of Acb shelllocalized AMPA receptors reduced PR breakpoint while increasing responding on the inactive lever. Together, these findings provide: (1) direct evidence for an opioid- and glutamate-coded functional interaction between the PFC and hypothalamus in cortically driven feeding, (2) evidence that opioid signaling in the vmPFC modulates the activity of $\mathrm{H} / \mathrm{O}-$ containing neurons, and (3) a demonstration of functionally dissociable roles of glutamate signaling within hypothalamus and ventral striatum in mediating PFC-driven food motivation.

\section{Implications for understanding frontal modulation of} hypothalamic feeding and arousal systems

A very low dose of AP-5 (20-fold lower than commonly used in the literature; Dalley et al., 2005; McKee et al., 2010), failed to alter intra-vmPFC DAMGO-induced hyperactivity while simultaneously blocking DAMGO-induced hyperphagia. These results suggest that AP-5 blocked a glutamate signal triggered in associ- 

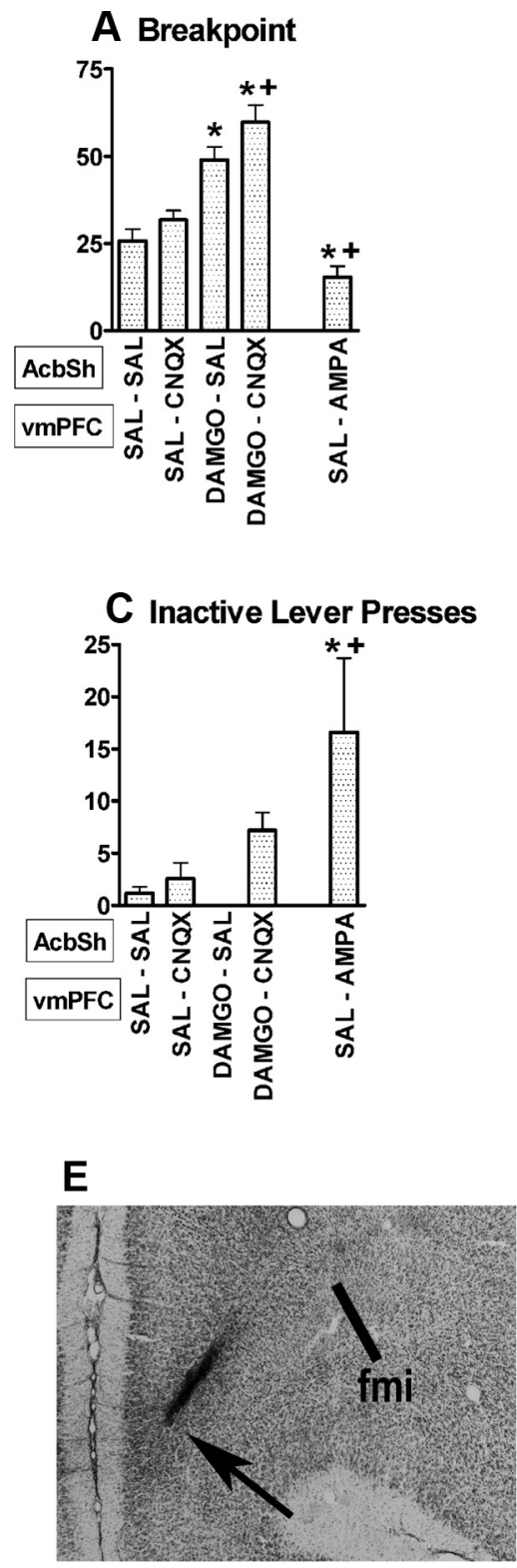
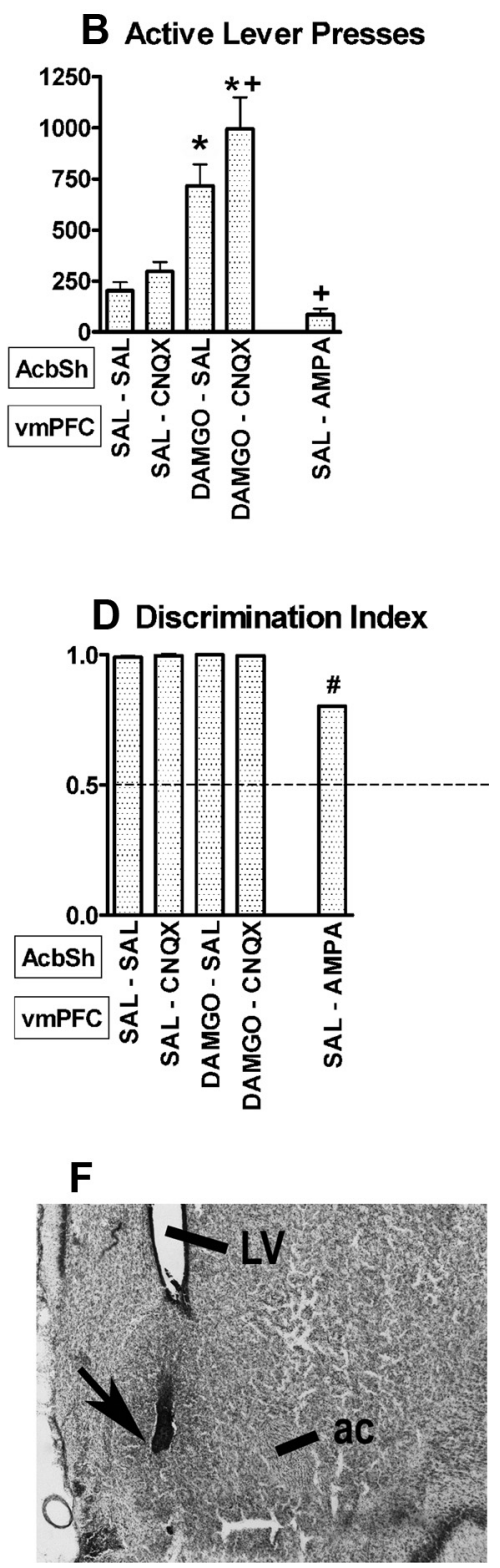

Figure 8. Effects of intra-Acb shell AMPA manipulations and intra-vmPFC DAMGO on PR responding. $A$, Shows breakpoint (the last successfully completed ratio requirement). $\boldsymbol{B}, \boldsymbol{C}$, Show responding on the active and inactive levers, respectively. $\boldsymbol{D}$, Shows discrimination index, the ratio of correct responses to total responses $(1.00$ reflects perfect discrimination, 0.5 reflects chance responding or loss of discrimination). $\boldsymbol{A}-\boldsymbol{D},{ }^{*} p<0.05$, different from Sal-Sal and Sal-CNQX; $+p<0.05$, different from DAMG0-Sal. Error bars indicate 1 SEM. Photomicrographs illustrate typical placements in the $\operatorname{vmPFC}(\boldsymbol{E})$ and Acb shell $(\boldsymbol{F})$. Arrows point to injector tips. Fmi, forceps of corpus callosum; ac, anterior commissure; LV, lateral ventricle.

ation with the vmPFC manipulation, and was not simply the consequence of generalized motor suppression or antagonism of a permissive glutamatergic tone. This vmPFC/hypothalamus interaction may be mediated either by the monosynaptic glutamatergic projection originating from vmPFC, or through a polysynaptic pathway. Regardless, the fact that hypothalamic glutamate signaling engendered by intra-vmPFC $\mu \mathrm{OR}$ stimulation is sufficient to provoke feeding under low-drive, lowincentive conditions (ad libitum-maintained rats offered standard chow) suggests that opioid signaling in the PFC can "hijack" hypothalamic systems to promote nonhomeostatic feeding. This may have implications for dysregulated feeding in psychopathology. For example, $\mu \mathrm{OR}$ blockade ameliorates some symptoms of bingeeating disorder (BED; Berner et al., 2011; Ziauddeen et al., 2012), and an imaging study indicated that frontal regions are overactivated in BED patients in response to food-related stimuli (Schienle et al., 2009). The present results may implicate a $\mathrm{vmPFC/hypothalamus} \mathrm{circuit} \mathrm{in} \mathrm{these}$ effects.

$\mu$ OR stimulation in the vmPFC was also sufficient to elevate Fos expression in the medial tuberal hypothalamus and to activate $\mathrm{H} / \mathrm{O}$-containing neurons in this zone. This region is similar to a zone under excitatory control by infralimbic cortex during extinction expression (Marchant et al., 2010). Importantly, Fos levels provoked by intra-vmPFC DAMGO were significantly higher than those seen after exposure to a novel environment, indicating that the DAMGO-induced increase was not simply the consequence of greater alert waking relative to saline control. The H/O system has been studied extensively with regard to its role in narcolepsy; more generally, this system is thought to engage and maintain waking and to couple arousal and appetitive motivation (Estabrooke et al., 2001; Tsujino and Sakurai, 2009). Exogenous administration of $\mathrm{H} / \mathrm{O}$, either intraventricularly or directly into the LH-PeF, engenders feeding, and this response requires NMDA receptor activation within the region (Sakurai et al., 1998; Kotz et al., 2002; Thorpe et al., 2003; Doane et al., 2007). Hence, intra-vmPFC DAMGOinduced feeding may be mediated by the glutamatergic activation of $\mathrm{H} / \mathrm{O}$ neurons, although further experiments are needed to fully test this hypothesis.

There is growing evidence that $\mathrm{H} / \mathrm{O}$ regulates addiction-related processes, including drug-induced place preference, drug withdrawal effects, and the reinstatement of extinguished drug-seeking behavior (for review, see Aston-Jones et al., 2010). Germane to the present results, lesions of rat PFC reduced nicotine-induced activation of $\mathrm{H} / \mathrm{O}$ neurons (Pasumarthi and Fadel, 2010), and, strikingly, amphetamine-sensitized rats show augmented amphetamine-induced Fos expression specifically within $\mathrm{mPFC}$ neurons retrogradely labeled with an intra-LH, but not intra-Acb, tracer injections (Morshedi and Meredith, 2008). Hence, through a vmPFC/hypothalamus functional interaction, excessive intra-vmPFC opioid signaling may engender dysregulated appetitive behavior not only with regard to feeding, but also in addiction (Cason et al., 2010; Morganstern et al., 2011).

Implications for understanding circuit interactions among vmPFC, Acb shell, and hypothalamus

The vmPFC, Acb shell, and LH-PeF are heavily interconnected (Thompson and Swanson, 2010); functional interactions among these sites are complex and not fully understood. Nevertheless, 
evidence is accumulating to suggest that glutamate-coded vmPFC/LH and vmPFC/Acb shell pathways mediate dissociable and perhaps opposing functions in appetitive behavior. Electrical or glutamatergic stimulation of the LH-PeF elicits feeding (Wise, 1974; Stanley et al., 1993; Berthoud and Münzberg, 2011; Li et al., 2011); furthermore, nonhomeostatic feeding provoked by an appetitive pavlovian cue activates PFC neurons marked by tracer infusions into the LH-PeF but not the Acb (Petrovich and Gallagher, 2007). These findings, together with the present results, indicate that a glutamate-coded vmPFC-hypothalamus interaction promotes appetitive behavior.

In contrast, stimulation of Acb shell-localized AMPA-type glutamate receptors suppresses feeding (Stratford et al., 1998), and electrical stimulation of the nucleus accumbens immediately arrests consummatory sucrose licking (Krause et al., 2010). Conversely, AMPA (but not NMDA) blockade or chemical inactivation of the Acb shell provokes feeding; importantly, this feeding effect is thought to be mediated by LH activity (MaldonadoIrizarry et al., 1995; Kelley and Swanson, 1997; Stratford and Kelley, 1999). Electrophysiological studies revealed a subpopulation of Acb neurons that show inhibitions that begin immediately before the onset of consummatory sucrose licking and persist during consumption, but do not occur during locomotion unrelated to consumption (Taha and Fields, 2005, 2006; Krause et al., 2010). In a conceptually related finding, a subpopulation of Acb shell units showed phasic inhibitions during instrumental actions and sucrose-receptacle entries; basal activity of these units was suppressed by vmPFC lesions, suggesting that these neurons are under excitatory control by vmPFC projections (Ghazizadeh et al., 2012). Together, these findings suggest that the glutamatergic projection from the vmPFC to the Acb shell has the capacity to suppress specific goal-directed behaviors via AMPA-mediated activation of a specific "appetitive response-gating" neuron population. Finally, along with inhibiting feeding, intra-Acb shell AMPA infusion also engenders considerable exploratory-like behavior (ambulation) (Stratford et al., 1998), and unilateral AMPA but not NMDA stimulation in the Acb shell elicits intense motor activation manifested as contraversive rotational behavior (Ikeda et al., 2003). These results indicate that AMPA signaling in the Acb shell recruits motor repertoires that are incompatible with feeding.

Accordingly, we found that, while intrahypothalamus NMDA blockade reduced DAMGO-driven feeding, AMPA blockade in the Acb shell augmented both food intake and sucrose-reinforced PR responding. Moreover, intra-Acb shell CNQX reduced DAMGO-induced locomotor hyperactivity, and infusion of AMPA alone into the Acb shell reduced PR breakpoint while engendering nonspecific responding on the inactive lever. These findings are consistent with the hypothesis that the disorganized behavioral phenotype of feeding/hyperactivity elicited by intravmPFC DAMGO may be an emergent property of the simultaneous recruitment of multiple downstream targets of vmPFC projections, such as the LH-PeF and Acb shell. Key to this idea is the hypothesis that excessive intra-vmPFC $\mu \mathrm{OR}$ signaling produces supernormal PFC activation and glutamatergic outflow, perhaps through $\mu$-OR-mediated suppression of a local inhibitory network (Taki et al., 2000; Witkowski and Szulczyk, 2006; Férézou et al., 2007). This is not unlike the proposed mechanism for opioid actions in the hippocampus (Zieglgänsberger et al., 1979; Madison and Nicoll, 1988; Capogna et al., 1993; McQuiston, 2007). With regard to circuit connections, a recent study found a closed-loop anatomical relationship among infralimbic PFC, Acb shell (similar to the zone targeted here), ventral palli- dum, and a tightly circumscribed anterior LH region, via a thalamic relay (Thompson and Swanson, 2010). However, vmPFC innervates widespread hypothalamic areas beyond the anterior $\mathrm{LH}$, including tuberal hypothalamic levels studied in the present work (Hurley et al., 1991; Floyd et al., 2001; Vertes, 2004). Hence, AMPA signaling in the closed-loop vmPFC-Acb shell circuit could engage a behavioral set that competes with or "interrupts" specific goal-directed appetitive behaviors (see discussion in Baldo and Kelley, 2007), while glutamate transmission in broader hypothalamic areas simultaneously engages appetitive drive. Such a mechanism could underlie the "fragmented" locomotor/ feeding profile seen here, and possibly dysregulated feeding responses and breakdown in executive control seen in binge-type eating disorders.

\section{Conclusions}

The present results may have important clinical implications. Recent evidence suggests that the PFC is a crucial site of opioid action in several "disorders of appetitive motivation," including addiction (Gorelick et al., 2005; Chang et al., 2010; Colasanti et al., 2012; Mitchell et al., 2012); however, to date, the subcortical network through which intra-PFC $\mu \mathrm{OR}$ signaling modifies behavior and cognition has not been characterized. The present work begins to elucidate key nodes in this network, and moreover suggests that behavioral disorganization produced by intra-PFC $\mu \mathrm{OR}$ stimulation results from dysregulated activation of functionally diverse nodes (including recruitment of specific peptide systems downstream of the PFC). These insights may suggest treatment strategies that combine $\mu \mathrm{OR}$ blockade (which shows some efficacy against food binging and drug craving (O'Brien, 2005; Berner et al., 2011) with rationally selected manipulation of substrates within subcortical PFC projection targets.

\section{References}

Aston-Jones G, Smith RJ, Sartor GC, Moorman DE, Massi L, Tahsili-Fahadan P, Richardson KA (2010) lateral hypothalamic orexin/hypocretin neurons: a role in reward-seeking and addiction. Brain Res 1314:74-90. CrossRef Medline

Baldo BA, Kelley AE (2007) Distinct neurochemical coding of discrete motivational processes: insights from nucleus accumbens control of feeding. Psychopharmacology 191:439-459. CrossRef Medline

Baldo BA, Gual-Bonilla L, Sijapati K, Daniel RA, Landry CF, Kelley AE (2004) Activation of a subpopulation of orexin/hypocretin-containing hypothalamic neurons by GABAA receptor-mediated inhibition of the nucleus accumbens shell, but not by exposure to a novel environment. Eur J Neurosci 19:376-386. CrossRef Medline

Baldo BA, Alsene KM, Negron A, Kelley AE (2005) Hyperphagia induced by GABAA receptor-mediated inhibition of the nucleus accumbens shell: dependence on intact neural output from the central amygdaloid region. Behav Neurosci 119:1195-1206. CrossRef Medline

Berner LA, Bocarsly ME, Hoebel BG, Avena NM (2011) Pharmacological interventions for binge eating: lessons from animal models, current treatments, and future directions. Curr Pharm Des 17:1180-1187. CrossRef Medline

Berthoud HR, Münzberg H (2011) The lateral hypothalamus as integrator of metabolic and environmental needs: from electrical self-stimulation to opto-genetics. Physiol Behav 104:29-39. CrossRef Medline

Blasio A, Steardo L, Sabino V, Cottone P (2013) Opioid system in the medial prefrontal cortex mediates binge-like eating. Addict Biol. Advance online publication. doi: 10.1111/adb. 12033 .

Bodnar RJ (2004) Endogenous opioids and feeding behavior: a 30-year historical perspective. Peptides 25:697-725. CrossRef Medline

Capogna M, Gähwiler BH, Thompson SM (1993) Mechanism of mu-opioid receptor-mediated presynaptic inhibition in the rat hippocampus in vitro. J Physiol 470:539-558. Medline

Cason AM, Smith RJ, Tahsili-Fahadan P, Moorman DE, Sartor GC, AstonJones G (2010) Role of orexin/hypocretin in reward-seeking and addic- 
tion: implications for obesity. Physiol Behav 100:419-428. CrossRef Medline

Chang GQ, Barson JR, Karatayev O, Chang SY, Chen YW, Leibowitz SF (2010) Effect of chronic ethanol on enkephalin in the hypothalamus and extra-hypothalamic areas. Alcohol Clin Exp Res 34:761-770. CrossRef Medline

Colasanti A, Searle GE, Long CJ, Hill SP, Reiley RR, Quelch D, Erritzoe D, Tziortzi AC, Reed LJ, Lingford-Hughes AR, Waldman AD, Schruers KR, Matthews PM, Gunn RN, Nutt DJ, Rabiner EA (2012) Endogenous opioid release in the human brain reward system induced by acute amphetamine administration. Biol Psychiatry 72:371-377. CrossRef Medline

Dalley JW, Lääne K, Theobald DE, Armstrong HC, Corlett PR, Chudasama Y, Robbins TW (2005) Time-limited modulation of appetitive Pavlovian memory by D1 and NMDA receptors in the nucleus accumbens. Proc Natl Acad Sci U S A 102:6189-6194. CrossRef Medline

Doane DF, Lawson MA, Meade JR, Kotz CM, Beverly JL (2007) Orexininduced feeding requires NMDA receptor activation in the perifornical region of the lateral hypothalamus. Am J Physiol Regul Integr Comp Physiol 293:R1022-R1026. CrossRef Medline

Duva MA, Tomkins EM, Moranda LM, Kaplan R, Sukhaseum A, Bernardo JP, Stanley BG (2002) Regional differences in feeding and other behaviors elicited by N-methyl-D-aspartic acid in the rodent hypothalamus: a reverse microdialysis mapping study. Brain Res 925:141-147. CrossRef Medline

Estabrooke IV, McCarthy MT, Ko E, Chou TC, Chemelli RM, Yanagisawa M, Saper CB, Scammell TE (2001) Fos expression in orexin neurons varies with behavioral state. J Neurosci 21:1656-1662. Medline

Férézou I, Hill EL, Cauli B, Gibelin N, Kaneko T, Rossier J, Lambolez B (2007) Extensive overlap of mu-opioid and nicotinic sensitivity in cortical interneurons. Cereb Cortex 17:1948-1957. CrossRef Medline

Floyd NS, Price JL, Ferry AT, Keay KA, Bandler R (2001) Orbitomedial prefrontal cortical projections to the hypothalamus in the rat. J Comp Neurol 432:307-328. CrossRef Medline

Gabbott PL, Warner TA, Jays PR, Salway P, Busby SJ (2005) Prefrontal cortex in the rat: projections to subcortical autonomic, motor, and limbic centers. J Comp Neurol 492:145-177. CrossRef Medline

Ghazizadeh A, Ambroggi F, Odean N, Fields HL (2012) Prefrontal cortex mediates extinction of responding by two distinct neural mechanisms in accumbens shell. J Neurosci 32:726-737. CrossRef Medline

Gorelick DA, Kim YK, Bencherif B, Boyd SJ, Nelson R, Copersino M, Endres CJ, Dannals RF, Frost JJ (2005) Imaging brain mu-opioid receptors in abstinent cocaine users: time course and relation to cocaine craving. Biol Psychiatry 57:1573-1582. CrossRef Medline

Gosnell BA, Levine AS (2009) Reward systems and food intake: role of opioids. Int J Obes 33 [Suppl 2]:S54-S58. CrossRef Medline

Hahn JD, Swanson LW (2010) Distinct patterns of neuronal inputs and outputs of the juxtaparaventricular and suprafornical regions of the lateral hypothalamic area in the male rat. Brain Res Rev 64:14-103. CrossRef Medline

Haile CN, Kosten TA, Kosten TR (2008) Pharmacogenetic treatments for drug addiction: alcohol and opiates. Am J Drug Alcohol Abuse 34:355381. CrossRef Medline

Hurley KM, Herbert H, Moga MM, Saper CB (1991) Efferent projections of the infralimbic cortex of the rat. J Comp Neurol 308:249-276. CrossRef Medline

Ikeda H, Akiyama G, Fujii Y, Minowa R, Koshikawa N, Cools AR (2003) Role of AMPA and NMDA receptors in the nucleus accumbens shell in turning behaviour of rats: interaction with dopamine receptors. Neuropharmacology 44:81-87. CrossRef Medline

Kelley AE, Berridge KC (2002) The neuroscience of natural rewards: relevance to addictive drugs. J Neurosci 22:3306-3311. Medline

Kelley AE, Swanson CJ (1997) Feeding induced by blockade of AMPA and kainate receptors within the ventral striatum: a microinfusion mapping study. Behav Brain Res 89:107-113. CrossRef Medline

Khan AM, Watts AG (2004) Intravenous 2-deoxy-D-glucose injection rapidly elevates levels of the phosphorylated forms of p44/42 mitogenactivated protein kinases (extracellularly regulated kinases $1 / 2$ ) in rat hypothalamic parvicellular paraventricular neurons. Endocrinology 145: 351-359. Medline

Kotz CM, Teske JA, Levine JA, Wang C (2002) Feeding and activity induced by orexin A in the lateral hypothalamus in rats. Regul Pept 104:27-32. CrossRef Medline
Krause M, German PW, Taha SA, Fields HL (2010) A pause in nucleus accumbens neuron firing is required to initiate and maintain feeding. J Neurosci 30:4746-4756. CrossRef Medline

Li FW, Deurveilher S, Semba K (2011) Behavioural and neuronal activation after microinjections of AMPA and NMDA into the perifornical lateral hypothalamus in rats. Behav Brain Res 224:376-386. Medline

Madison DV, Nicoll RA (1988) Enkephalin hyperpolarizes interneurones in the rat hippocampus. J Physiol 398:123-130. Medline

Maldonado-Irizarry CS, Swanson CJ, Kelley AE (1995) Glutamate receptors in the nucleus accumbens shell control feeding behavior via the lateral hypothalamus. J Neurosci 15:6779-6788. Medline

Marchant NJ, Furlong TM, McNally GP (2010) Medial dorsal thalamus mediates the inhibition or reward seeking after extinction. J Neurosci 30: 14102-14115. CrossRef Medline

McKee BL, Kelley AE, Moser HR, Andrzejewski ME (2010) Operant learning requires NMDA-receptor activation in the anterior cingulate cortex and dorsomedial striatum, but not in the orbitofrontal cortex. Behav Neurosci 124:500-509. Medline

McQuiston AR (2007) Effects of mu-opioid receptor modulation on GABAB receptor synaptic function in hippocampal CA1. J Neurophysiol 97:2301-2311. CrossRef Medline

Mena JD, Sadeghian K, Baldo BA (2011) Induction of hyperphagia and carbohydrate intake by mu-opioid receptor stimulation in circumscribed regions of frontal cortex. J Neurosci 31:3249-3260. CrossRef Medline

Mitchell JM, O'Neil JP, Janabi M, Marks SM, Jagust WJ, Fields HL (2012) Alcohol consumption induces endogenous opioid release in the human orbitofrontal cortex and nucleus accumbens. Sci Transl Med 4:116ra6. CrossRef Medline

Morganstern I, Barson JR, Leibowitz SF (2011) Regulation of drug and palatable food overconsumption by similar peptide systems. Curr Drug Abuse Rev 4:163-173. CrossRef Medline

Morshedi MM, Meredith GE (2008) Repeated amphetamine administration induces Fos in prefrontal cortical neurons that project to the lateral hypothalamus but not the nucleus accumbens or basolateral amygdala. Psychopharmacology 197:179-189. CrossRef Medline

O'Brien CP (2005) Anticraving medications for relapse prevention: a possible new class of psychoactive medications. Am J Psychiatry 162:14231431. CrossRef Medline

Pasumarthi RK, Fadel J (2010) Stimulation of lateral hypothalamic glutamate and acetylcholine efflux by nicotine: implications for mechanisms of nicotine-induced activation of orexin neurons. J Neurochem 113:10231035. CrossRef Medline

Paxinos G, Watson C (2007) The rat brain in stereotaxic coordinates, Ed. 6. San Diego: Academic.

Petrovich GD, Gallagher M (2007) Control of food consumption by learned cues: a forebrain-hypothalamic network. Physiol Behav 91:397-403. CrossRef Medline

Peyron C, Tighe DK, van den Pol AN, de Lecea L, Heller HC, Sutcliffe JG, Kilduff TS (1998) Neurons containing hypocretin (orexin) project to multiple neuronal systems. J Neurosci 18:9996-10015. Medline

Sakurai T, Amemiya A, Ishii M, Matsuzaki I, Chemelli RM, Tanaka H, Williams SC, Richarson JA, Kozlowski GP, Wilson S, Arch JR, Buckingham RE, Haynes AC, Carr SA, Annan RS, McNulty DE, Liu WS, Terrett JA, Elshourbagy NA, Bergsma DJ, et al. (1998) Orexins and orexin receptors: a family of hypothalamic neuropeptides and $\mathrm{G}$ protein-coupled receptors that regulate feeding behavior. Cell 92:1 page following 696. CrossRef Medline

Schienle A, Schäfer A, Hermann A, Vaitl D (2009) Binge-eating disorder: reward sensitivity and brain activation to images of food. Biol Psychiatry 65:654-661. CrossRef Medline

Stanley BG, Willett VL 3rd, Donias HW, Ha LH, Spears LC (1993) The lateral hypothalamus: a primary site mediating excitatory amino acidelicited eating. Brain Res 630:41-49. CrossRef Medline

Stanley BG, Willett VL 3rd, Donias HW, Dee MG 2nd, Duva MA (1996) Lateral hypothalamic NMDA receptors and glutamate as physiological mediators of eating and weight control. Am J Physiol 270:R443-R449. Medline

Stratford TR, Kelley AE (1999) Evidence of a functional relationship between the nucleus accumbens shell and lateral hypothalamus subserving the control of feeding behavior. J Neurosci 19:11040-11048. Medline

Stratford TR, Swanson CJ, Kelley A (1998) Specific changes in food intake elicited by blockade or activation of glutamate receptors in the nucleus accumbens shell. Behav Brain Res 93:43-50. CrossRef Medline

Taha SA, Fields HL (2005) Encoding of palatability and appetitive behaviors 
by distinct neuronal populations in the nucleus accumbens. J Neurosci 25:1193-1202. CrossRef Medline

Taha SA, Fields HL (2006) Inhibitions of nucleus accumbens neurons encode a gating signal for reward-directed behavior. J Neurosci 26:217-222. CrossRef Medline

Taki K, Kaneko T, Mizuno N (2000) A group of cortical interneurons expressing mu-opioid receptor-like immunoreactivity: a double immunofluorescence study in the rat cerebral cortex. Neuroscience 98:221-231. CrossRef Medline

Thompson RH, Swanson LW (2010) Hypothesis-driven structural connectivity analysis supports network over hierarchical model of brain architecture. Proc Natl Acad Sci U S A 107:15235-15239. CrossRef Medline

Thorpe AJ, Mullett MA, Wang C, Kotz CM (2003) Peptides that regulate food intake: regional, metabolic, and circadian specificity of lateral hypothalamic orexin A feeding stimulation. Am J Physiol Regul Integr Comp Physiol 284:R1409-R1417. Medline

Tsujino N, Sakurai T (2009) Orexin/hypocretin: a neuropeptide at the interface of sleep, energy homeostasis, and reward system. Pharmacol Rev 61:162-176. CrossRef Medline

Vertes RP (2004) Differential projections of the infralimbic and prelimbic cortex in the rat. Synapse 51:32-58. CrossRef Medline
Wessinger WD (1986) Approaches to the study of drug interactions in behavioral pharmacology. Neurosci Biobehav Rev 10:103-113. CrossRef Medline

Wise RA (1974) Lateral hypothalamic electrical stimulation: does it make animals 'hungry'? Brain Res 67:187-209. CrossRef Medline

Witkowski G, Szulczyk P (2006) Opioid mu receptor activation inhibits sodium currents in prefrontal cortical neurons via a protein kinase A- and C-dependent mechanism. Brain Res 1094:92-106. CrossRef Medline

Woolverton W (1987) Analysis of drug interactions in behavioral pharmacology. In: Neurobehavioral pharmacology (Thompson T, Dews PB, Barrett JE, eds), pp 275-302. Hillsdale, NJ: Lawrence Erlbaum Associates.

Ziauddeen H, Chamberlain SR, Nathan PJ, Koch A, Maltby K, Bush M, Tao WX, Napolitano A, Skeggs AL, Brooke AC, Cheke L, Clayton NS, Sadaf Farooqi I, O'Rahilly S, Waterworth D, Song K, Hosking L, Richards DB, Fletcher PC, Bullmore ET (2012) Effects of the mu-opioid receptor antagonist GSK1521498 on hedonic and consummatory eating behaviour: a proof of mechanism study in binge-eating obese subjects. Mol Psychiatry. Advance online publication. doi: 10.1038/mp. 2012.154.

Zieglgänsberger W, French ED, Siggins GR, Bloom FE (1979) Opioid peptides may excite hippocampal pyramidal neurons by inhibiting adjacent inhibitory interneurons. Science 205:415-417. CrossRef Medline 